\title{
DERECHO Y VIOLENCIA: LA “OBJETIVIDAD” COMO ESPACIO DE SU INDISTINCIÓN. EL CASO DE LA CONSTITUCIÓN CHILENA DE 1980.
}

\author{
JAIME BASSA MERCADO' ${ }^{*}$ \\ NICOLÁS FUSTER SÁNCHEZ ${ }^{* *}$ \\ CHRISTIAN VIERA ALVAREZ $3^{3^{* * *}}$
}

\section{Resumen.}

El presente trabajo tiene por objetivo explorar la compleja relación entre derecho y violencia. De este modo, se propone una lectura crítica de los mecanismos de interpretación que buscan anular la dimensión política de los enunciados constitucionales. Particularmente, se analiza el "originalismo" presente en la dogmática chilena que ha permitido la apelación a la objetividad de la norma fundamental sobre la base de la verdad que subyace en la idea de origen. Siguiendo la discusión propuesta por la Teoría Crítica -Benjamin, Foucault, entre otros-se ponen en tensión los supuestos que han permitido anular el debate sobre el contenido político de la Constitución chilena de 1980.

\section{Palabras clave:}

Originalismo - Discurso - Verdad - Constitucionalismo

\footnotetext{
Abstract.

This paper explores the complex relationship between law and violence.

1 * Doctor en derecho. Profesor titular Escuela de Derecho, Universidad de Valparaíso, Valparaíso, Chile, jaime.bassa@uv.cl.

$2 \quad$ *** Doctor en ciencias sociales. Profesor titular Escuela de Enfermería, Universidad de Valparaíso, Viña del Mar, Chile, nicolas.fuster@uv.cl

3 **** Doctor en derecho. Profesor titular Escuela de Derecho, Universidad de Valparaíso, Valparaíso, Chile, christian.viera@uv.cl
} 
It proposes a critical reading of the interpretation mechanisms that try to override the political dimensions of the Constitution. In particular, it analyzes the "originalism" of the Chilean constitutionalism that appeals to the objectivity of the Constitution, founded in the notion of truth hidden behind the idea of origin. Following the critical theory approach -Benjamin, Foucault, among others- the paper questions the assumptions that set aside the debate on the political content of the 1980 Chilean Constitution.

\section{Key words:}

Originalism - Discourse - Truth - Constitutionalism

\section{La violencia fundadora del derecho}

Una de las cuestiones que posee una gravedad ontológica significativa y que recorre el trabajo de Walter Benjamin es la pregunta por la relación que puede trazarse entre violencia y derecho ${ }^{4}$, o más bien, sobre la violencia que subyace al derecho. ${ }^{5}$ En un texto titulado Hacia la crítica de la violencia y publicado en 1921, Benjamin señala:

"Se dirá que un sistema de fines jurídicos no podrá sostenerse mientras queden fines naturales cuya obtención se pueda perseguir con violencia. Pero eso es un dogma simplemente. Contra él, quizá se pueda recurrir a la sorprendente posibilidad de que el interés del derecho en la monopolización de la violencia frente a las personas individuales no se explique mediante la intención de salvaguardar los fines jurídicos, sino, antes bien, mediante la intención de salvaguardar el derecho como tal; pues la violencia, si no se encuentra en manos del derecho, lo pone en peligro, no mediante los

$4 \quad$ En esta misma dirección, Jaques Derrida señala: "Hay ciertamente leyes que no se aplican, pero no hay ley sin aplicabilidad, y no hay aplicabilidad, o enforceability de la ley, sin fuerza, sea ésta directa o no, física o simbólica, exterior o interior, brutal o sutilmente discursiva -0 incluso hermenéutica-, coercitiva o regulativa, etc. ¿Cómo distinguir entre, de una parte, esta fuerza de la ley, esta $<<$ fuerza de ley $>>$ como se dice tanto en francés como en inglés, creo, y de otra, la violencia que se juzga siempre injusta? ¿Qué diferencia existe entre, de una parte, la fuerza que puede ser justa, en todo caso legítima (no solamente el instrumento al servicio del derecho, sino el ejercicio y el cumplimiento mismos, la esencia del derecho) y, de otra parte, la violencia que se juzga siempre injusta? ¿Qué es una fuerza justa o una fuerza no violenta?", en DERRIDA, Jacques: Fuerza de ley. El fundamento místico de la autoridad. Tecnos, Madrid, 2010. Págs. 16-17.

5 GALENDE, Federico: Walter Benjamin y la destrucción. Metales Pesados, Santiago, 2009. Pág. 74. 
fines que persigue, sino ya por el hecho de su mera existencia externa al derecho". ${ }^{6}$

En este sentido, el derecho y su ejercicio, según Benjamin, no pueden desligarse de la violencia, ya que son recíprocos. Es decir, la violencia es el medio del derecho, y por lo tanto, es su fuerza instauradora y conservadora. ${ }^{7}$ Esto significaría que la violencia no es anterior al derecho, ni tampoco es sólo un efecto "residual" de su ejercicio, sino más bien "es lo que lo configura a través de un movimiento que va desde su "instauración arbitraria', en tanto fuerza, a su mantención y conservación, en tanto poder, y viceversa". ${ }^{8}$ Esta fuerza instauradora, que erige a la norma, al derecho y a su estado, al Estado de Derecho, siempre es violenta, ya que opera borrando la huella de su origen, es decir, anulando la legalidad de un "estado anterior" y naturalizando un origen que pasa ahora a ser la palabra iniciática del legislador. Como señala Galende: "en la medida que el derecho no puede dar cuenta de su 'razón constitutiva', siempre es un hecho de violencia el que determine la emergencia de este derecho: se trata de la violencia 'fundadora'. Y este es el motivo por el cual, por medio de una especie de segundo paso, el derecho, una vez fundado por esta violencia, se mantiene a través del rechazo de cualquier otra violencia que no sea la que lo configura". ${ }^{9}$ Esta relación intrínseca entre derecho y violencia deja en vilo cualquier tipo de análisis dogmático que no considere lo explícito de este vínculo. Es por lo anterior que conceptos tan importantes para nuestra tradición política, como son los de soberanía y de poder constituyente según Giorgio Agamben, deben repensarse o, derechamente, ser abandonados, ya que ambos invisibilizan la relación sinérgica entre violencia y derecho: "Uno y otro señalan el punto de indiferencia entre violencia y derecho, naturaleza y logos, propio e impropio, y, como tales, no designan un atributo o un órgano del orden jurídico o del Estado, sino su propia estructura original (...) la soberanía es el guardián que impide que el umbral indecible entre violencia y derecho, naturaleza y lenguaje salga a la luz". ${ }^{10}$

6 BENJAMIN, Walter: "Hacia la crítica de la violencia". En: Benjamin, Walter: Obras, Libro II, Vol. 1. Abada Editores, Madrid, 2010. Págs. 186-187.

7 Ibídem. Pág. 193.

8 GALENDE, Federico, ob. cit. Pág. 75.

9 Ibídem. Págs. 77-78.

10 AGAMBEN, Giorgio: Medios sin fin. Notas sobre la política. Pre-Textos, Valencia, 2010. Págs. 95-96. 
La escena teleológica del estado de derecho (derecho de estado) que caracterizó a la primera parte del siglo xx chileno se suspendió el 11 de septiembre de 1973, dejando en vilo la operatividad de la Constitución de 1925. El levantamiento de las tres ramas de las Fuerzas Armadas más Carabineros devino en golpe de estado. Con el golpe militar, la derecha reaccionaria asume no sólo la administración del gobierno, sino también el control social, iniciando el diseño y la implementación de un nuevo modelo económico y político. La junta militar se aboca, prácticamente el mismo día del golpe, al estudio de una nueva Constitución. En efecto, por medio del DS 1064 se "designa Comisión para que estudie, elabore y proponga un Anteproyecto de una nueva Constitución Política del Estado". ${ }^{11} \mathrm{La}$ fundamentación del DS señala que la Comisión se establece "considerando la necesidad de reconstruir, renovar y perfeccionar la institucionalidad fundamental de la República". ${ }^{12}$

En esta dirección, la Constitución de 1980 es paradigmática en relación al binomio derecho/violencia. Como explica Willy Thayer,

"el Golpe, la tortura, al mismo tiempo de ejercerse, suspenden el 'Estado de derecho' en función y resguardo del cual supuestamente habría de ejercitarse. El Golpe, la tortura, 'suspende la constitución moderna in toto' drenando el ejercicio de la fuerza del derecho moderno. La ley fuera de la ley es, entonces, la ley. El fundamento reprimido de la ley, lo que la prohíbe para erigirse, retorna como norma. La excepción se convierte en norma. La violencia contra lo ilimitado gira en violencia contra el límite". ${ }^{13}$

Muñoz insiste en la misma idea:

"el castigo desencadenado tras el golpe contra la insubordinación popular fue brutal; la crueldad con que los militares reprimieron, y la insensibilidad con que sus aliados civiles negaron o derechamente justificaron la violencia, convierte este período en nuestro propio evento de mal radical, según la expresión utilizada por Hannah Arendt para describir el genocidio realizado por los nazis [...] Es inevitable, debido a estas referencias, discutir este concepto sin evocar la idea arendtiana de la

11 DS $\mathrm{N}^{\circ} 1.064$, de 25 de octubre de 1973, del Ministerio de Justicia, que crea oficialmente la Comisión Constituyente, Diario Oficial, $\mathrm{N}^{\circ} 28.699$, Santiago, 12 de noviembre de 1973. Llamamos la atención sobre el paradojal nombre de la Comisión, "Constituyente", en circunstancias que el poder constituyente fue auto atribuido por la junta de gobierno, como lo señaló el Decreto Ley $N^{\circ} 1$ de 11 de septiembre de 1973.

12 Ibídem. "Vistos".

13 THAYER, Willy: El fragmento repetido. Escritos en estado de excepción. Metales Pesados, Santiago, 2006. Págs. 23-24. 
banalidad del mal, esto es, de la posibilidad de que el mal sea, en el caso incluso de actores claves en la gestión del terror, tan solo una expresión de conformismo burocrático, de obediencia de órdenes". ${ }^{14}$

En efecto, el vínculo entre derecho y violencia que opera dentro del orden jurídico dictatorial permite sentar las bases para la imposición de un orden nuevo que buscará, posteriormente, borrar ese lazo mediante la exclusión o la negación de la violencia que no sólo lo funda, sino que se aloja en íntima cercanía con la norma. Como explica Benjamin, no se trata, entonces, de la necesidad de anular la violencia, sino de incluirla de modo particular dentro del ordenamiento jurídico. Si bien el orden jurídico normal está en continua suspensión (no sólo por la interrupción de facto, sino también por la derogación, por ejemplo) la violencia no puede aparecer desnuda: se reviste y racionaliza, no se le permite una existencia completamente azarosa, aunque la zona de indistinción entre derecho y violencia abarque todo el territorio y gran parte de la operación del Estado. ${ }^{15}$

De este modo, el vínculo entre la ley y la violencia es completamente funcional al carácter productivo que instala la dictadura chilena y que tiene, hoy por hoy, una gran rentabilidad en su continnum. ${ }^{16}$ La naturalización de la fuerza que da origen a la dictadura -en la figura jurídica del legislador en tanto fantasmagoría de una violencia fundacional- niega todo proyecto político y social anterior (y el cuerpo social que se había constituido), a través de la crueldad racionalizada se eliminan sistemáticamente los lazos no sólo de movimientos que reivindiquen aquel proyecto, sino en general del país. Los lazos sociales destruidos son rearmados violentamente, sobre un territorio neutralizado a raíz de la violencia sistemática, es decir, se aloja la violencia en el seno del derecho que se impone, y que se intenta legitimar, a través de la Constitución de 1980. Esto, sin embargo, nunca puede considerarse un proceso completo, hasta que pueda instalarse un

14 MUÑOZ LEÓN, Fernando: Hegemonía y Nueva Constitución. Dominación, Subalternidad y Proceso Constituyente. Ediciones UACh, Valdivia, 2015. Págs. 80-81.

15 BENJAMIN, Walter: La dialéctica en suspension. Fragmentos sobre la historia. Editorial Arcis-LOM, Santiago, 1995. Pág. 194.

16 Al respecto, Willy Thayer señala: "El pasaje a la globalización que opera la Dictadura, la escena de la modernización del país en los 2000, es el documento de cultura que ha dialectizado el documento de barbarie. Y en esta borradura, el cepillo a contrapelo del Informe Rettig y del Informe Valech, no consiguen interrumpir la dialéctica progresista del país; parecen irrumpir convertidos en documentos historicistas, sumidos en la intencionalidad de una modernización general que hace bien las cosas. No insistir en la relación entre el Golpe, la tortura, la Dictadura y la actualidad triunfal, sería hacerse acólito del continuum de violencia y progreso", en THAYER, Willy, ob. cit. Pág. 39. 
discurso completamente otro sobre la violencia patente. Muñoz lo refiere acertadamente:

"el mal desencadenado a partir del 11 de septiembre de 1973 consistió en una forma instrumental de mal: un mal encaminado a la aniquilación de todos quienes disintieran del nuevo arreglo social deseado por los secuaces civiles de los militares insurrectos. En lugar de un arreglo social incluyente, la violencia dictatorial buscó crear las condiciones para el establecimiento del dominio de una sola clase, la clase de los propietarios [...] las detenciones ilegales, la tortura y el exilio, los fusilamientos y las desapariciones, la represión de la protesta, fueron instrumentos que tenían un propósito específico y deliberado: desactivar el disenso. Constituyen, por ello, un agonicidio, un exterminio de los que luchan". ${ }^{17}$

El proceso se completa solamente en la inclusión (vía negación y exclusión formal) de la violencia fundadora de la Constitución en el orden "apacible" del derecho. Esto adviene solamente dada la continuación de la misma Carta en una post-dictadura que, evidentemente, debe llamarse a sí misma democracia. Es esta segunda borradura que no sólo niega el origen violento de la Constitución chilena, sino que niega la relación intrínseca y manifiesta de la ley y la violencia, de la crueldad y la racionalidad, alojada en su interior, la que es posibilitada por la "transición democrática".

En esta dirección, creemos que la indistinción entre derecho y violencia opera a través de los criterios de objetividad que sectores de la dogmática jurídica esgrimen para la interpretación de la norma. En este ejercicio de interpretación "objetiva" se desnudaría una relación doblemente vinculante: por un lado, la interpretación remite a un origen pretendidamente prístino de la norma, al fantasma del legislador-constituyente (violencia fundadora) $\mathrm{y}$, por otra parte, a un efecto práctico y estratégico: la sentencia que decide para proteger el sentido originario (violencia que mantiene). De esta forma, la acción de decir "esto es" -y todo el dispositivo que se activa en esta simple locución- anuda y, al mismo tiempo borra la huella a una violencia que "funda" no sólo la realidad, sino también su legalidad (es decir, sus límites). Al respecto, Lanceros señala que:

"todo ejercicio de definición consiste en la implementación de límites y fronteras, en el establecimiento de un territorio habitable y en la correlativa heterodesignación de un entorno inhóspito u hostil (que opera, con la venida de Derrida, como exterior constitutivo del interior constituyente). Dicha 
definición, aunque se ejerza en el ámbito del discurso -o precisamente por ello-es un ejercicio de poder, un acto político (en sentido amplio); aunque sólo sea por el hecho de que de-fine o de-limita el que puede hacerlo, el que tiene poder para ello y ocupa una determinada posición: que tiende a imponerse. Los límites y fronteras producidos por la definición suelen, además, generar aranceles y peajes". ${ }^{18}$

Ese acto de de-finición realizado a través de la interpretación que apela al origen de la Carta es, en consecuencia, parte de esa misma violencia constitutiva del ordenamiento constitucional impuesto por la dictadura.

\section{Discurso, verdad y poder}

La controvertida relación entre derecho y violencia ha tenido una alta rentabilidad teórica, dando pie a diversas interpretaciones sobre la monopolización legítima de la fuerza por parte del Estado y de la ley que lo funda. Sin embargo, la dogmática jurídica y las lecturas más conservadoras del fenómeno del derecho moderno han invisibilizado dicha relación a través argumentos basados en las ideas de interpretación y objetividad. En esta dirección, Mouffe señala que "toda objetividad social está constituida por actos de poder. Esto significa que toda objetividad social es en último término política y debe mostrar las huellas de los actos de exclusión que rigen su constitución". ${ }^{19}$ Por tanto, cualquier ejercicio de lectura de la norma no podría desconocer el carácter político del ejercicio interpretativo en el que tanto el saber jurídico como el poder político emergerían como elementos imbricados en el acto interpretativo. Es por esto que las sentencias del Tribunal Constitucional (en adelante, TC), en tanto resultados de su interpretación objetiva, son capaces de naturalizar una cierta perspectiva sobre la realidad social. Primer peligro: la naturalización de los discursos es el efecto más evidente del poder que ejerce el saber y la verdad sobre las sociedades. Este "efecto" sería, según Foucault, el resultado de la vinculación estratégica entre el discurso y los objetos de los que este habla. De ahí la necesidad de "no tratar -en dejar de tratar- los discursos como conjunto de signos (de elementos significantes que envían a contenidos o

18 LANCEROS, Patxi: Avatares del Hombre. El pensamiento de Michel Foucault. Universidad de Deusto, Bilbao, 1996. Pág. 114.

19 MOUFFE, Chantal: La paradoja democrática: El peligro del consenso en la política contemporánea. Gedisa, Barcelona, 2016. Pág. 38. 
a representaciones), sino como prácticas que forman sistemáticamente los objetos de que hablan". ${ }^{20}$

Esta capacidad de dar vida a conceptos, objetos, estrategias, enunciados, para luego hablar de ellos desde la distancia necesaria que exige la objetividad jurídica, nos revela el carácter apofántico del TC, ya que sus sentencias se asemejan a un sistema de saber, es decir, a un "espacio en que un sujeto puede tomar posición para hablar de los objetos de que trata en su discurso". ${ }^{21}$ En este sentido, la objetividad de la interpretación que realiza el TC de la norma fundamental, la Constitución Política, estaría dada por una cierta función práctica-social que buscaría posicionar los objetos de los que habla para, posteriormente, darles una interpretación funcional a ciertos fines de clase. En definitiva, para pensar la interpretación como un problema político debemos centrarnos en los efectos de poder de aquellos discursos que dicen la verdad y que, de este modo, pretenden legitimar el ejercicio de ciertas prácticas políticas o, incluso, constitucionales. Desde este punto de vista, el poder y la verdad serían las claves de inteligibilidad para leer el problema de la interpretación constitucional. Un par de ejemplos nos permiten justificar esta afirmación, ya que el Tribunal Constitucional, independiente de su composición, por la importancia que tiene en las estructuras para el ejercicio del poder, termina siendo un órgano que afecta la deliberación democrática, principalmente a través del control preventivo.

A propósito del subsidio postnatal, en 2012 se promulgó la ley que aumentaba el tiempo de permiso, pero estableciendo un tope de ingresos en la extensión del segundo trimestre, permiso que recibe el nombre de subsidio postnatal parental. Un grupo de funcionarias públicas recurre de inaplicabilidad al Tribunal Constitucional para que declare contrario a la Constitución la norma que establece ese tope porque establece, principalmente, un criterio de discriminación arbitrario. Por cierto, el requerimiento es rechazado, entre otras razones por la opinión del Tribunal Constitucional en torno a los derechos sociales: “[...] En efecto, el permiso posnatal parental y el subsidio estatal asociado a éste se orientan en el sentido preciso de dar cumplimiento a tales normas - independiente de los mecanismos y jerarquía internos de la recepción del Derecho Internacional en Chile - dentro de las posibilidades presupuestarias y apreciando

FOUCAULT, Michel: La arqueología del saber. Siglo XXI, Buenos Aires, 2011, Pág. 80. 
soberanamente el nivel de desarrollo del país compatible con ello". ${ }^{22}$ Tras esta afirmación hay una opinión y decisión política del Tribunal en relación a los derechos sociales: los derechos sociales tienen un costo y su satisfacción depende de las concretas circunstancias económicas de un Estado. Este argumento, el más típico para rechazar su entidad de tal a los derechos sociales, es discutible porque los derechos sociales, al igual que los civiles y políticos, están asociados a la idea de ciudadanía. ${ }^{23}$

Algo parecido ocurrió en la sentencia que revisó la constitucionalidad de la ley 21.030 que regula la despenalización de la interrupción voluntaria del embarazo en tres causales de septiembre de 2017. Si bien el Tribunal declaró la conformidad con la Constitución de las tres causales, en materia de objeción de conciencia agregó que se trata de un derecho que corresponde no sólo a las personas naturales sino que también a las personas jurídicas. Conviene recordar que en materia de derechos fundamentales, el problema de la titularidad ha sido escasamente desarrollado en Chile. ${ }^{24}$ Por lo mismo, no es extraño que en una forzada interpretación literal extiendan el derecho a la objeción de conciencia a las personas jurídicas: "no se divisa razón jurídica alguna para restringir la objeción de conciencia solamente a las personas naturales que revistan la condición de profesionales. Cuando aquéllas que no lo son también podrían tener reparos, en conciencia, frente a los procedimientos en que deben intervenir". ${ }^{25} \mathrm{Y}$ en qué se funda la objeción de conciencia: la dignidad humana. Dice el Tribunal que "la objeción de conciencia, en la forma planteada por el proyecto de ley que regula la despenalización de la interrupción voluntaria del embarazo en tres causales, debe entenderse amparada por la dignidad de las personas que - individualmente o proyectada en su asociación con otros se niegan a practicar cierto tipo de actuaciones (la interrupción del embarazo), por razones éticas, morales, religiosas, profesionales, u otras de señalada

$22 \quad$ STC Rol N$^{\circ} 2250-2012$, de 18 de junio de 2013, considerando $33^{\circ}$.

23 Cf. PISARELLO, Gerardo: Los derechos sociales y sus garantías. Trotta, Madrid, 2007; ATRIA, Fernando: Derechos sociales y educación: un nuevo paradigma de los público. LOM, Santiago, 2014.

24 La respuesta a la pregunta de la titularidad de los derechos fundamentales ha sido más bien formalista y de interpretación literal. Sin embargo, una justificación sustantiva se puede encontrar en ALDUNATE LIZANA, Eduardo: Derechos Fundamentales. Lexis Nexis, Santiago, 2007. Págs. 147-162; CONTRERAS, Pablo: "Titularidad de los derechos fundamentales". En: Contreras, Pablo y Salgado, Constanza (eds.): Manual sobre derechos fundamentales. LOM, Santiago, 2017. Págs. 119-160.

$25 \quad$ STC Rol N $3729-17$, de 28 de agosto de 2017, considerando $135^{\circ}$. 
relevancia". ${ }^{26}$ Es decir, a través de las personas que integran la Institución se proyecta, se extiende la dignidad de las personas a las Instituciones.

Sin perjuicio que hay autores que defienden la objeción de conciencia institucional para el caso del aborto, ${ }^{27}$ como también legislaciones de Argentina, EEUU y Francia, ${ }^{28}$ éste ha sido el camino que ha seguido el Tribunal Constitucional: "la objeción de conciencia puede ser planteada legítimamente por sujetos jurídicos o asociaciones privadas, en este caso, con arreglo a la autonomía constitucional que a los grupos intermedios de la sociedad les reconoce la propia Carta Fundamental [...]. La interposición de este legítimo reparo no se agota en el orden individual, puesto que también se extiende y propaga a las asociaciones destinadas a encarnar el mismo libre pensamiento". ${ }^{29}$ Sin embargo, es problemática la adscripción de este derecho a los colectivos ya que éstos no tienen convicciones, no tienen un pensamiento, a lo sumo un ideario que proponer a los individuos. Se produce, en estas hipótesis el equívoco que a nivel de las agrupaciones serán los directivos o sus dueños (las personas naturales) quienes reemplazan la conciencia individual de quienes trabajan en ellas, imponiendo una convicción propia y, por cierto, amenazando la estabilidad laboral en el evento de disentir. Pero sobre todo, porque las prestaciones sanitarias (como es el caso del aborto) son un servicio público con independencia de quien lo entrega. En estos supuestos, tendrán derecho a objetar las personas naturales que se desempeñen como profesionales de salud, pero no las Instituciones. Y eso fue lo que decidió el Congreso Nacional, criterio que fue rechazado por el Tribunal, con el consabido efecto de transformarse en legislador negativo.

Finalmente, el caso de le titularidad sindical. En 2017 se publicó la ley $\mathrm{N}^{\circ} 20.940$ que moderniza el sistema de relaciones laborales. Entre muchos

$26 \quad$ Ibíd, considerando $131^{\circ}$.

27 Cf. VIVANCO, Ángela: "La objeción de conciencia como derecho constitucional. Una especial mención a la objeción de conciencia ante la despenalización de la interrupción voluntaria del embarazo en tres causales, propuesta en el caso chileno". En: Casas Becerra, Lidia y Lawson, Delfina (comps.): Debates y reflexiones en torno a la despenalización del aborto en Chile. Centro de Derechos Humanos, Universidad Diego Portales, Santiago, 2015. Págs. 196-201; y NÚÑEZ, Manuel: "Convicciones éticas institucionales y objeción de conciencia colectiva en el sector sanitario público y privado". En: Casas Becerra, Lidia y Lawson, Delfina (comps.): Debates y reflexiones en torno a la despenalización del aborto en Chile. Centro de Derechos Humanos, Universidad Diego Portales, Santiago, 2015. Págs. 221223.

28 Ibíd. Págs. 221-222.

29 STC Rol N $3729-17$, de 28 de agosto de 2017, considerando $136^{\circ}$. 
aspectos, el proyecto original establecía que en el caso de la empresa o empresas que contaran con sindicato, solo con ellos se podía negociar colectivamente. En ausencia de sindicatos, se podía negociar con "grupos negociadores". La finalidad de la titularidad, fortalecer el protagonismo de los sindicatos como actores que representan a los trabajadores en los procesos de negociación y por lo mismo, su poder frente al empleador en esta relación vertical. Sin embargo, desde una lectura económica, resulta una amenaza a un modelo económico que se funda en la flexibilidad laboral y en la precariedad de las condiciones laborales. Por lo mismo, no es saludable fortalecer a los sindicatos. Con motivo de la aprobación del proyecto de ley, un grupo de senadores de la derecha chilena presentaron un requerimiento de inconstitucionalidad respecto del proyecto de ley que 'Moderniza el sistema de relaciones laborales' que introducía modificaciones al Código del Trabajo, entre las que se cuenta, la titularidad sindical. ${ }^{30}$

Por cierto, el Tribunal el Tribunal "acogerá en su totalidad el primer capítulo de impugnación (titularidad sindical)" ${ }^{31}$ Sin perjuicio que se trata de una larga sentencia, lo que está de fondo es una concepción de la libertad que canoniza su comprensión en términos negativos. Si esto es así, se postula por el Tribunal una dimensión antropológica radicalmente individualista, lo que no es sino una de las tantas maneras de comprender la tensión entre persona - libertad - igualdad. El problema es que esa lectura resulta impuesta y tiene efectos políticos, en este caso concreto, para un mejor desarrollo de los derechos de los trabajadores: "que, asimismo, hay que tener en consideración que la libertad de un trabajador de no afiliarse a un sindicato es un bien que resulta particularmente sensible para la Constitución, la que es garantizada con claridad, especificidad y consistencia a lo largo de su texto. Indicativo de lo anterior es la siguiente afirmación de un autor: [...] 'el numeral 19 contemplaría un reconocimiento mucho más contenido del derecho de los trabajadores a sindicarse ("en los casos y formas que señale la ley"); reconocimiento que, además, enfatiza los aspectos de libertad negativa antes que la dimensión de libertad positiva. De allí que se declare que "la afiliación sindical será siempre voluntaria", y que, a la hora de hablar de autonomía, se aluda más al derecho a la no injerencia externa hacia el sindicato que a la posibilidad del sindicalismo de desplegar influencia o presión hacia afuera" ${ }^{32}$

$30 \quad$ STC, Rol No 3016 (3026)-16, de 9 de mayo de 2016.

31 Ibíd, considerando $3^{\circ}$.

32 Ibíd, considerando $78^{\circ}$. 
Lo que queremos mostrar con estos tres ejemplos es que el Tribunal Constitucional, en los casos difíciles, termina imponiendo una decisión que no sólo colisiona con la deliberación democrática sino que también es manifestación de un poder que se ha ido construyendo poco a poco $\mathrm{y}$ que termina tocando una realidad social cada vez mayor. Y sigamos con los ejemplos, partimos con mujeres embarazadas; luego sindicatos; las personas jurídicas y un derecho para objetar; más adelante serán las Universidades. El poder del Tribunal va colonizando espacios enteros.

Siguiendo a Foucault, no se puede pensar al poder ni como una sustancia, ni como una fuerza detentada de manera particular por alguien o algo, ni tampoco como algo que se ejerce de forma unidireccional y absoluta. Más bien, el poder carecería de atributos universales y sólo se podría, en al ámbito de su análisis, lograr describir sus mecanismos y efectos en contextos históricos puntuales. Como señala Lanceros, "el poder surge de todos los puntos en los que se dan relaciones y atraviesa el espacio social entero configurando espacios homogéneos, efectos de escisión, alineamientos". ${ }^{33}$ Es decir, preguntarse por el poder implica necesariamente preguntarse por sus efectos en un espacio determinado. Frente a la objetividad basada en universales, Foucault instala un análisis de la especificidad. Desligarse de los universalismos históricos, del a priori, nos permite analizar las racionalidades que se dan en cada forma particular y específica de ejercicio de poder, ya que no existiría una gran racionalidad respecto de la cual los otros ejercicios de poder resultarían irracionales. Sino, más bien, de lo que se trataría es de describir la especificidad de cada forma de racionalidad para desarticular aquella que se nos presenta como única. Al respecto, Lanceros señala que para Foucault "nada se da sino en el marco de una racionalidad específica. Tal racionalidad específica es el orden o estructura fundamental, el espacio epistemológico específico de una determinada época: la episteme. Y lo que se trata de mostrar, evidentemente, no es su carácter necesario o ahistórico sino, por el contrario, su historicidad, su contingencia. El orden aparecerá como el a priori histórico, condición de posibilidad de la experiencia en una época dada". ${ }^{34}$

Esta mirada crítica de los ejercicios y efectos del poder tendría, entonces, su centro de atención en el binomio verdad-poder y, por efecto, en las tecnologías y dispositivos de sometimiento que esta imbricación permite extender y difundir. El objetivo básico de este análisis anti-esencialista 
será mostrar la forma en que las objetividades sociales que las ciencias consideran como naturales y preexistentes son, de hecho, efectos de prácticas objetivadoras y resultado de luchas de poder previas que los han hecho, finalmente, posibles. Y para llevar a cabo esta labor de oteador, que es al mismo tiempo una labor de desvelamiento, es necesario describir y comprender el mecanismo íntimo que regula la producción de los discursos que se pretenden verdaderos, sacando a la luz la huella que han dejado las luchas históricas involucradas en su constitución.

\section{La historicidad de la objetividad jurídica: el "originalismo"}

La doctrina constitucional que acompañó las primeras décadas desde la promulgación de la Constitución -tanto en dictadura como en el período que sigue a 1990- se caracterizó por asumir de manera acrítica un dato muy cuestionable desde la perspectiva de la propia teoría constitucional contemporánea: que aquello aprobado en 1980 era, en efecto, una Constitución en plena regla. Como consecuencia de ello, dicha doctrina ha sistematizado este cuerpo normativo desde una pretensión de normalidad tanto institucional como disciplinar, estudiando su contenido dogmáticamente e interpretándolo como sui fuera el resultado de una voluntad soberana y democrática, propiamente constituyente. Para ello recurrió en forma acrítica y permanente a las actas de la Comisión de Estudios para una Nueva Constitución (CENC), concebidas como fuente de interpretación auténtica. Esta decisión refleja una determinada concepción de la Constitución y de su interpretación: que el texto se entiende desde un único contenido posible, el que puede ser alumbrado con ayuda de las Actas, depositarias de la verdad oficial. Con esta lectura de la interpretación constitucional, se ha logrado petrificar el contenido de proyecto político de la dictadura, restringiendo fuertemente la posibilidad de que el pueblo participe democráticamente en la construcción de su ordenamiento jurídico, perpetuando ese momento de violencia constitutiva que explica la propia existencia del régimen.

En tanto corriente hermenéutica, este originalismo supone una tensión constante entre el momento constituyente y el de aplicación de la norma fundamental, donde lo que está en disputa es la preferencia que debe tener uno u otro momento en la interpretación de la Carta vigente. Se trata de una corriente propia de la tradición constitucional angloamericana, que surge como una reacción conservadora a la jurisprudencia de la Suprema Corte de Estados Unidos durante las décadas de 1960 y 1970, bajo las 
presidencias de los jueces Warren y Burger. En un contexto de ampliación de la protección de derechos civiles, que la Corte estaba empujando a través de la interpretación del texto constitucional, fue acusada de incumplir su deber de fidelidad a la intención original de sus redactores, vulnerando la función judicial al crear derechos por vía hermenéutica. El primer originalismo fue contrario a sentencias emblemáticas de la Corte (especialmente Roe vs. Wade, que reguló la interrupción voluntaria del embarazo en 1973). Con el correr de los años, la reacción inicial fue mutando en tanto crítica a una práctica judicial, desde la defensa de la original intent hacia un original meaning, trasladando el énfasis a la fidelidad de los jueces hacia la Constitución, antes que de restringir su actuar. ${ }^{35}$ Esta dimensión del originalismo acepta que se trata de una teoría de interpretación y no de adjudicación constitucional, reconociendo el alto grado de indeterminación de un texto fundamental, especialmente respecto de los derechos fundamentales. ${ }^{36}$

Aunque el originalismo chileno no tuvo el grado de desarrollo teórico que muestra la tradición angloamericana, parte de la doctrina nacional pretendió imponer al intérprete un único sentido posible del texto constitucional, uno que solo podía ser debidamente identificado mediante las Actas. Esta perspectiva identifica como una legítima manifestación del poder constituyente al trabajo realizado por la CENC; ésta ha definido el contenido de la Constitución, el que debe ser respetado por la interpretación constitucional cualquiera sea su sede. ${ }^{37}$ De esta forma, la violencia del momento constituyente se proyecta a través de la interpretación de una de sus principales manifestaciones normativas. Sin embargo, la función de una Constitución es garantizar la apertura del sistema democrático, protegiendo los mínimos necesarios para la convivencia pacífica, una

35 SMITH, Peter: "How different are Originalism and Non-Originalism?". En: Hastings Law Review, Hastings College of the Law, University of California, Vol. 62, $\mathrm{N}^{\circ} 3$, 2011. Págs. 711-713; POWELL, Jefferson: "The Original Understanding of Original Intent". En: Harvard Law Review, Vol. 98, № 5, 1985. Págs. 885 y ss.

36 BALKIN, Jack: "Original meaning and Constitutional Redemption". En: Faculty Scholarship Series, Yale Law School, Paper 227, 2007; SOLUM, Lawrence: "What is originalism? The evolution of contemporary originalist theory". En: Social Science Research Network, Georgetown University Law Center, 2011. Disponible en: http://dx.doi.org/10.2139/ ssrn. 1825543.

$37 \quad$ BASSA MERCADO, Jaime: "La pretensión de objetividad como una estrategia para obligar. La construcción de cierta cultura de hermenéutica constitucional hacia fines del siglo XX”. En: Estudios Constitucionales, Facultad de Derecho, Universidad de Talca, Vol. 11, N², 2013. Pág. 34. 
norma fundamental debe garantizar la apertura para la concretización del contenido de los enunciados normativos ${ }^{38}$ y no restringir la discusión política para proteger la estabilidad de un proyecto político partisano. Al hacerlo, quienes son titulares del poder para definir lo constitucional se yerguen en reemplazo de lo político. Lo que ha generado la interpretación constitucional originalista es la permanencia del proyecto político de la década de 1970, cerrando el debate democrático con el recurso a la interpretación originalista identificada en las Actas.

Las reformas más significativas a la Constitución vigente -en 1989 y 2005- modificaron parcialmente el diseño original, eliminando algunos de los llamados enclaves autoritarios destinados a proteger el régimen político diseñado por la dictadura. Luego de las diversas reformas constitucionales que siguen a 1989, es posible afirmar que la Carta vigente está un poco más acerca del modelo propio de las democracias occidentales que del diseñado en dictadura. Las reformas constitucionales han desarticulado la tutela militar sobre el sistema político, así como algunas de las principales instituciones a través de las cuales se implementó (aunque los elementos nucleares del sistema económico y político se mantienen a través de las leyes orgánico-constitucionales (LOC), que ha excluido ciertas materias del debate público). Sin embargo, dichos cambios han sido sistemáticamente neutralizados, como consecuencia de haber vinculado la interpretación de la Carta a las opiniones vertidas en el seno de la CENC, impidiendo que su contenido sea actualizado democráticamente. ${ }^{39}$ Ello ha generado una disociación entre la Constitución y la comunidad política que la legitima, lo que se manifiesta, preferentemente, en la persistente reivindicación por una asamblea constituyente.

Cualquier método de interpretación constitucional se fundamenta en una teoría de lo constitucional que le antecede y condiciona el resultado de la interpretación. Adoptar un determinado método no es una decisión valorativamente neutra, sino que responde a una finalidad determinada: que la interpretación arribe a cierto resultado. ${ }^{40}$ Desde esta perspectiva, el originalismo a la chilena no solo es un método de interpretación,

$38 \quad$ HESSE, Konrad: “Concepto y cualidad de la Constitución”. En: Hesse, Konrad: Escritos de Derecho constitucional. Centro de Estudios Políticos y Constitucionales, Madrid, 2011. Pág. 46. 39 En todo caso, la doctrina más reciente muestra una superación de este criterio hermenéutico: BASSA MERCADO, Jaime, ob. cit. Pág. 34.

40 BASSA MERCADO, Jaime: "Neutralidad política y enseñanza del Derecho Constitucional en Chile". En: Henríquez, Miriam (coord.): Perspectiva del Derecho Constitucional desde el mirador del Bicentenario. Asociación Chilena de Derecho Constitucional, Santiago, 2011. Págs. 285-286. 
sino un dispositivo de poder propiamente tal, que integra una teoría constitucional previa y subyacente, obedeciendo a determinada concepción de la Constitución, como el testamento político de la dictadura. Dicha concepción asume que el poder constituyente -identificado en la CENCha definido el contenido de la Norma Fundamental y los intérpretes deben respetarlo. Como dicho contenido ya habría sido definido, no podría ser alterado mediante interpretación. Aquí hay mucho más que un empobrecimiento en el desarrollo dogmático de la disciplina a través de una interpretación cognoscitivista. Se trata de una determinada teoría de la interpretación constitucional que utiliza la pretendida objetividad de la norma como un argumento político para someter a los detractores del proyecto constitucional construido durante la dictadura de Pinochet. ${ }^{41}$

\section{La indeterminación de enunciados constitucionales: una estrategia objetivadora}

La propuesta teórica de Alexy ${ }^{42}$ relativa a la clasificación de las normas constitucionales atendiendo a su estructura -reglas y principios-, ha encontrado una importante recepción en el constitucionalismo latino (especialmente España, Italia y América Latina). Postula que en atención al tipo de mandato que contiene una norma con estructura de regla, su interpretación puede ser concebida en términos de todo o nada, cuyo mandato (diríamos en Chile) podría sujetarse a los criterios de interpretación de la ley, tradicionalmente identificados en los artículos 19 a 24 del Código Civil. Sin embargo, dicha pretensión fracasaría respecto de las normas constitucionales con estructura de principio, pues su apertura e indeterminación impiden establecer criterios objetivos de interpretación, debido a que el mandato que contienen sería uno de optimización del principio consagrado.

Esta indeterminación abre un espacio de discrecionalidad en la interpretación constitucional, ${ }^{43}$ el que podría ser concebido como

$41 \quad$ BASSA MERCADO, Jaime, "La pretensión de objetividad como una estrategia para obligar...", ob. cit. Págs. 33-35.

42 ALEXY, Robert: Teoría de los derechos fundamentales. Centro de Estudios Constitucionales, Madrid, 2002. Págs. 81 y ss.

43 ATRIA, Fernando: "Los peligros de la Constitución. La idea de igualdad en la jurisdicción constitucional”. En: Cuadernos de Análisis Jurídico, Facultad de Derecho, Universidad Diego Portales, N 36, 1992. Págs. 25-81; ATRIA, Fernando: "El Tribunal Constitucional y la objeción democrática". En: Revista Chilena de Derecho, Facultad de Derecho, Pontificia Universidad Católica de Chile, Vol. 20, N²-3, 1993. Págs. 367 y ss. 
una manifestación positiva en el contexto de un Estado de Derecho constitucional y democrático. En efecto, la apertura estructural de las normas constitucionales supone una garantía de libertad para una comunidad política, por cuanto la posibilidad de concretar su contenido en el futuro queda disponible, sin que sea necesario dictar una nueva Constitución. Dada la diversidad cultural de las sociedades contemporáneas, no es posible esperar que una Constitución imponga un proyecto de sociedad particular. Por el contrario, una Constitución debe ser una garantía de tal diversidad. Las diversas modificaciones que ha experimentado el modelo de constitución desde la crisis del Estado liberal de Derecho dan cuenta de cómo la diversidad ideológica y social se ha incorporado al paradigma constitucional contemporáneo, por lo que no es posible esperar que una constitución se identifique con una de las múltiples concepciones de la convivencia democrática que hoy dan forma a las sociedades contemporáneas.

Las normas de derechos fundamentales evidencian cómo las constituciones contemporáneas cumplen una función distinta a la del siglo XIX. Ya no se trata solo del estatuto que organiza el ejercicio del poder dentro de la institucionalidad estatal o de la declaración formal que garantiza la titularidad sobre derechos de libertad. El siglo xx nos muestra cómo cambió el concepto de Constitución, especialmente mediante la constitucionalización de derechos que dan cobertura a intereses y necesidades distintas de aquellas que protagonizaron las revoluciones burguesas. Ya no se trata, solo, de proteger espacios de libertad frente a la intervención estatal, sino de garantizar ciertas condiciones materiales de existencia, necesarias para el ejercicio de los derechos proclamados en las primeras declaraciones. ${ }^{44}$

En ese contexto, la apertura de las normas de principio podría reflejar la diversidad políticay cultural propia de tres tradiciones del constitucionalismo, que se proyectan los catálogos de derechos fundamentales: liberal, social y democrática, que representan intereses y necesidades reivindicados por diversos grupos sociales, los que son constitucionalizados en condiciones de universalidad. Se trata, en definitiva, de una manifestación del Derecho

$44 \quad$ FIORAVANTI, Maurizio: Los derechos fundamentales. Apuntes de historia de las constituciones. Trotta, Madrid, 2016. Págs. 123 y ss. 
como una ciencia social que se construye desde los procesos políticos y culturales que caracterizan a una sociedad. ${ }^{45}$

En este contexto, la democracia constitucional y la soberanía popular como fuente de legitimidad tienen como finalidad -al menos discursivamente- garantizar un auto gobierno del pueblo limitado por ciertas reglas preliminares establecidas en la Constitución, especialmente las de derechos fundamentales. Pero a pesar de que se trata de normas destinadas a habilitar la convivencia democrática, su propia legitimidad es, a su vez, democrática, tal como lo evidencian los procesos históricos que han acompañado la progresiva ampliación de los catálogos de derechos. Cada etapa de la historia de los derechos que marca su evolución, ha estado marcada por procesos más o menos violentos, desde las revoluciones burguesas de fines del siglo XviII, pasando por las luchas contra totalitarismos, colonialismos y dictaduras durante el siglo xx, hasta las nuevas reivindicaciones de derechos civiles que han marcado el inicio del siglo XXI.

En clave histórica, el contenido de los catálogos de derechos resulta de una serie de luchas y conflictos verificados en los últimos trescientos años, cuya contingencia se proyecta hacia el futuro. Por ello, no es posible concebir que determinados contenidos materiales de la actual Constitución chilena, concebidos como mínimos por cierto sector de la doctrina y la jurisprudencia nacional, puedan ser excluidos del proceso deliberativo. Una decisión soberana puede igualmente alterarlos, pues estas reglas preliminares también forman parte de los procesos políticos. Dada la apertura de las normas de derechos fundamentales, cuyo contenido es determinado mediante la interpretación, es importante para la vigencia normativa de estas normas que gocen de suficiente legitimidad democrática.

Ahora bien, esta apertura de la Constitución se verifica en las normas de estructura abierta e indeterminada -especialmente por su carácter polisémico-, cuyo contenido material no puede ser fijado en forma definitiva por el constituyente; se trata de valores constitucionalizados cuya protección dependerá del contexto histórico, normativo y también fáctico de aplicación de la norma en cuestión. Asimismo, la apertura del texto constitucional se manifiesta en diversas materias cuya regulación queda abierta para una concretización legal posterior: ${ }^{46}$ la norma fundamental

45 DE CABO, Carlos: Pensamiento crítico, Constitucionalismo crítico. Trotta, Madrid, 2014. Págs. 9-13.

46 HESSE, Konrad, ob. cit. Pág. 46. 
aborda una serie de materias con diverso nivel de detalle, dada la dimensión normativa que cae dentro de la competencia tanto del constituyente como del legislador, más sensible a las relaciones políticas que se verifican en la sociedad en torno a las instituciones.

Así, la concretización de ciertas materias queda entregada a un acto normativo posterior al momento constituyente, generalmente de competencia del legislador. Sin embargo, la norma constitucional es estructuralmente distinta a la norma legal, pues forma parte de un sistema político más amplio y abierto, que configura al legislativo como un órgano de representación popular pero que actúa dentro de ciertos límites. Es esta relación tensa entre constituyente y legislador, que se verifica en los límites que supone la Constitución para la política, la que debe llevarnos a revisar críticamente si es posible determinar la voluntad objetiva de una norma. Apelar a dicha voluntad no solo es una manifestación de la concepción antropológica de la soberanía -propia de la transposición de las teorías bodianas a la soberanía popular-, sino que supone una recreación de la violencia constitutiva de un orden constitucional determinado, tributario de una determinada correlación de fuerzas políticas que rompió con u equilibrio anterior. Tratar de recuperar dicha voluntad supone revivir ciertas disputas sociales y, especialmente, perpetuar la forma en que fueron resueltas, incluso en contextos políticos y sociales diferentes.

Estamos en presencia de ciertos pisos mínimos que la Constitución contempla para la convivencia democrática de la sociedad, pero cuya concretización no es, ni puede ser, realizada en forma ahistórica en el momento constituyente. Por el contrario, de una forma más o menos consciente, el constituyente trataría de garantiza el espacio necesario para que sea la propia comunidad, manifestada a partir de su propio contexto histórico, la que realice (concretice, interprete) ese piso de reglas preliminares que se han positivado en la Constitución. Esta garantía de libertad política se manifiesta, principalmente, a través de las potestades normativas del legislador, en tanto principal órgano de representación política de las sensibilidades que componen a la sociedad, tanto de la mayoría como de las minorías (sentido democrático de la reserva de ley como garantía, por ejemplo, de la regulación de los derechos fundamentales). Sin embargo, muchas de las luchas que dieron vida al ordenamiento jurídico persisten durante su aplicación, por lo que el desafío para la apertura democrática del legislador es todavía mayor. 
La Constitución contemporánea es asumida como una estructura de normas que garantiza los mínimos necesarios para la convivencia democrática y no como la materialización de un determinado proyecto político de sociedad. Por eso se afirma que la Constitución debiera ser concebida como la positivación de ciertos mínimos éticos, reglas preliminares del juego democrático que están destinadas a garantizar su plena realización, mas no como un techo de máximos éticos, que restrinja las posibilidades de concretización y de realización de las normas constitucionales por parte de la sociedad. Esta lectura supone, precisamente, recrear constantemente la violencia constitutiva del orden que una constitución representa.

En nuestro medio se ha hablado de una Constitución de 'techo ideológico abierto'. ${ }^{47}$ El modelo de Constitución del actual Estado de Derecho sería tributario de la tradición del constitucionalismo contemporáneo (liberal, social y democrática), que reúne en un mismo texto los intereses y pretensiones que éstas representan. Los derechos que emanan de las revoluciones burguesas se identifican con los intereses económicos y culturales de determinado grupo social, reconocidos como derechos de titularidad universal. Lo propio sucede con las reivindicaciones sociales y las de carácter democratizador, que derivan, respectivamente, en la constitucionalización de los derechos sociales, en el fin de dictaduras y totalitarismos y en la calificación de discriminatorios de una serie de criterios que antes eran considerados razonables, como raza, sexo, religión, etc.

Este proceso histórico muestra la difícil positivación de los derechos, que responde al reconocimiento y protección de las necesidades e intereses de distintos sectores de la sociedad. El resultado de este proceso es un catálogo de derechos cuyo contenido es contingente y que proyecta, discursivamente, la igual valoración de los intereses que representan las tres tradiciones del constitucionalismo contemporáneo. Desde esta perspectiva, la única forma en que una Constitución garantice y proteja adecuadamente los intereses que provienen de estas tradiciones, es estableciendo las reglas mínimas, pero sin comprometerse con ninguna. La neutralidad ideológica que se predica del Estado debe predicarse también respecto de la Constitución, particularmente en un contexto cultural y normativo que se construye desde la constitucionalización del principio democrático. Lo

47 ZÚÑIGA URBINA, Francisco: "Reformas constitucionales para un Estado social y democrático de Derecho”. En: Colección Ideas, Año 4, N 33, 2003. Págs. 27-28. 
contrario supone recrear, permanentemente, la violencia constitutiva de este orden.

\section{La interpretación jurídica como instrumento político}

Dado que existe una diferencia entre el enunciado normativo y la norma propiamente tal, es decir, entre el tenor literal de una disposición y el Derecho que se aplica en virtud de ella, afirmamos que la objetividad no es posible en el conocimiento jurídico. La interpretación supone una transformación desde la subjetividad del intérprete, quien se apropia de lo conocido para después operar con el resultado de su proceso cognitivo. La aplicación del enunciado normativo supone una construcción argumentativa a partir de la cual el sujeto formula una interpretación e intenta argumentar que se trata de la correcta, mostrando diferentes niveles de compromiso con el objeto de estudio.

El contenido de la decisión judicial supone un cuestionamiento a la objetividad de la interpretación, no sólo porque es interpretable en sí mismo, sino porque pudo haber sido diferente cambiando al sujeto, o bien, la valoración de los materiales jurídicos disponibles. Su contenido se encuentra más determinado por las características personales del intérprete que por el enunciado normativo, del cual no se desprende una respuesta necesaria, sino que proyecta una serie de soluciones posibles, algunas de las cuales podrán ser adecuadas para determinado caso. Tras la norma no hay una única respuesta correcta, sino diversos significados que podrán ser adjudicados con mejores o peores argumentos; una "interpretación decisión" antes que "interpretación conocimiento", ${ }^{48}$ como lo demuestra la interpretación que realiza un órgano colegiado.

Ha sido la doctrina constitucional la que más ha contribuido a perpetuar la violencia originaria del orden vigente, al proponer una interpretación de lo constitucional anclada en una cierta concepción de la decisión constituyente y del papel que en su construcción tuvieron los órganos asesores de la dictadura. A partir de un enunciado normativo común, su interpretación responde a la combinación de diversas opciones que se pueden plantear frente a lo constitucional en tanto objeto de estudio (opciones metodológicas, epistemológicas, hermenéuticas, políticas), que condicionan su resultado. Dado que la indeterminación del enunciado

$48 \quad$ GUASTINI, Riccardo: Distinguiendo. Estudios de teoría y metateoría del Derecho. Gedisa, Barcelona, 1999. Págs. 203-204. 
constitucional es radical, su interpretación es clave para concretar un contenido normativo que, en ningún caso, es autoevidente.

Lo anterior explica, por ejemplo, las diversas lecturas que permite el artículo $19 \mathrm{~N}^{\circ} 1$ inciso $2^{\circ}$ de la Constitución, ya que la indeterminación del texto normativo permite levantar argumentos para sostener, simultáneamente, que la vida del que está por nacer tiene protección constitucional o simplemente legal, que se trata de un derecho fundamental, o bien, de un interés constitucional. El contenido de dicho enunciado no es autoevidente, por lo que la norma se construye desde interpretaciones que serán respaldas en argumentos mejores o peores. El contenido de la norma es una interpretación que no se verifica dentro del binomio correcta/ incorrecta, sino que desde una argumentación mejor/peor, según las opciones del intérprete.

Lo propio ocurre con el artículo $19 \mathrm{~N}^{\circ} 21$ inciso $2^{\circ}$ de la Carta, que establece el estatuto del Estado empresario, en cuya construcción la doctrina constitucional ha tenido una función mucho más determinante que la propia Constitución, que solo entrega competencia al legislador para fijas condiciones a la actividad económica del Estado. Parte de la doctrina nacional, la más cercana al proyecto político de la dictadura, ha sostenido que se trata de una constitucionalización del orden público económico, construido a partir del derecho de propiedad y del principio de subsidiariedad, dotando de contenido material al enunciado normativo. ${ }^{49}$ Sin embargo, el contenido del artículo no se identifica, necesariamente, con dicha lectura, sino que es el resultado de una opción política del intérprete, destinada a recrear el contenido del momento originario. Si el constitucionalismo chileno concibe el estatuto del Estado empresario como lo hace, se debe a su interpretación desde principios como el de subsidiariedad, en desmedro de otros como el de solidaridad, también reconocido en la Constitución.

El derecho no es inmune al contexto histórico y político en el que despliega su fuerza; es allí donde las normas jurídicas tienen vigencia. Dada la incidencia de las condiciones que hacen posible la imposición de una norma y su propia pervivencia más allá de dichas condiciones, es que la Constitución chilena no puede sustraerse de su génesis (violenta), como tampoco su vida posterior puede hacerlo respecto de la violencia que representa cada vez que es aplicada. Aunque se ha intentado naturalizar su contenido, permanentemente nos debemos hacer cargo de las dificultades

49 FERMANDOIS, Arturo: Derecho Constitucional Económico. Ediciones Universidad Católica de Chile, Santiago, 2006. Págs. 72-74. 
que genera una interpretación que, o bien colisiona con la vitalidad fáctica de una comunidad, o bien, sucumbe ante los intereses de ciertos intérpretes que buscan proteger su contenido y, con él, sus propias posiciones de privilegio.

No hay objetividad en las normas constitucionales, así como tampoco permanencia; lo que ellas digan estará condicionado por la contingencia y por la evolución que experimenta la comunidad que vive una Constitución. No obstante, para el caso chileno -y a pesar de tímidos intentos recientes como el llamado "proceso constituyente" durante el gobierno de la Presidenta Bachelet que buscaba un cambio de la Constitución- la de 1980 representa muy claramente la violencia que cierto sector de la sociedad ejerce desde el Estado, como imposición de un proyecto político a través de un estatuto jurídico. Que haya sido reformada en múltiples ocasiones no es reflejo de un nuevos acuerdos sociales, sino solo de cambios al nivel de las reglas constitucionales ${ }^{50}$ puesto que el ethos original de la Constitución sigue vigente, principalmente en los mecanismos neutralizadores del agenciamiento político del pueblo (como el TC, las LOC o su procedimiento de reforma), así como también en la interpretación con pretensión de objetivación que se hace desde la elite. En este sentido, "si la Unidad Popular es, para las clases dominantes, el momento del trauma, la Constitución de 1980 representa la salvación [...] la forma concreta, institucional, a través de la cual alcanza este objetivo es protegiendo el programa económico, social y político de la dictadura a través de reglas y procedimientos que dificultan la transformación de los pilares fundamentales". ${ }^{51} \mathrm{Al}$ parecer, no se observa una genuina voluntad política para enfrentar y superar el problema de legitimidad del sistema constitucional chileno.

50 SCHMITT, Carl: Teoría de la Constitución. Tecnos, Madrid, 2003. Págs. 47-52.

51 MUÑOZ LEÓN, Fernando, ob. cit. Pp. 97-98. 


\section{Bibliografía}

\section{Libros, capítulos de libros y artículos}

AGAMBEN, Giorgio: Medios sin fin. Notas sobre la política. Pre-Textos, Valencia, 2010.

ALDUNATE LIZANA, Eduardo: Derechos Fundamentales. Lexis Nexis, Santiago, 2007.

ALEXY, Robert: Teoría de los derechos fundamentales, Centro de Estudios Constitucionales, Madrid, 2002.

ATRIA, Fernando: "El Tribunal Constitucional y la objeción democrática". En: Revista Chilena de Derecho. Facultad de Derecho, Pontificia Universidad Católica de Chile, Vol. 20, N 2-3, 1993. Págs. 367-378.

ATRIA, Fernando: "Los peligros de la Constitución. La idea de igualdad en la jurisdicción constitucional". En: Cuadernos de Análisis Jurídico, Facultad de Derecho, Universidad Diego Portales, No 36, 1997.

ATRIA, Fernando: Derechos sociales y educación: un nuevo paradigma de lo público. LOM, Santiago, 2014.

BALKIN, Jack: "Original meaning and Constitutional Redemption". En: Faculty Scholarship Series, Yale Law School, Paper 227, 2007.

BASSA MERCADO, Jaime: "Neutralidad política y enseñanza del Derecho Constitucional en Chile". En: Henríquez, Miriam (coord.): Perspectiva del Derecho Constitucional desde el mirador del Bicentenario. Asociación Chilena de Derecho Constitucional, Santiago, 2011. Págs. 271-289.

BASSA MERCADO, Jaime: "La pretensión de objetividad como una estrategia para obligar. La construcción de cierta cultura de hermenéutica constitucional hacia fines del siglo XX". En: Estudios Constitucionales, Facultad de Derecho, Universidad de Talca, Vol. 11, N 2, 2013. Págs. 1546.

BENJAMIN, Walter: La dialéctica en suspensión. Fragmentos sobre la historia. Arcis-LOM, Santiago, 1995.

BENJAMIN, Walter: "Hacia la crítica de la violencia". En: Walter, Benjamin: Obras, Libro II, Vol. 1. Abada Editores, Madrid, 2010. 
CONTRERAS, Pablo: "Titularidad de los derechos fundamentales". En: Contreras, Pablo y Salgado, Constanza (eds.): Manual sobre derechos fundamentales. LOM, Santiago, 2017. Págs. 119-160.

DE CABO, Carlos: Pensamiento crítico, constitucionalismo crítico. Trotta, Madrid, 2014.

DERRIDA, Jacques: Fuerza de ley. El fundamento místico de la autoridad. Tecnos, Madrid, 2010.

FERMANDOIS, Arturo: Derecho Constitucional Económico. Ediciones Universidad Católica de Chile, Santiago, 2006.

FIORAVANTI, Maurizio: Los derechos fundamentales. Apuntes de historia de las constituciones. Trotta, Madrid, 2016.

FOUCAULT, Michel: La arqueología del saber. Siglo XXI, Buenos Aires, 2011.

GALENDE, Federico: Walter Benjamin y la destrucción. Metales Pesados, Santiago, 2009.

GUASTINI, Riccardo: Distinguiendo. Estudios de teoría y metateoría del Derecho. Gedisa, Barcelona, 1999.

HESSE, Konrad: “Concepto y cualidad de la Constitución”. En: Hesse, Konrad: Escritos de Derecho Constitucional. Centro de Estudios Políticos y Constitucionales, Madrid, 2011. Págs. 3-55.

LANCEROS, Patxi: Avatares del Hombre. El pensamiento de Michel Foucault. Universidad de Deusto, Bilbao, 1996.

MOUFFE, Chantal: La paradoja democrática: El peligro del consenso en la política contemporánea. Gedisa, Barcelona, 2016.

MUÑOZ LEÓN, Fernando: Hegemonía y Nueva Constitución. Dominación, Subalternidad y Proceso Constituyente. Ediciones UACh, Valdivia, 2015.

NÚÑEZ, Manuel: "Convicciones éticas institucionales y objeción de conciencia colectiva en el sector sanitario público y privado". En: Casas Becerra, Lidia y Lawson, Delfina (comps.): Debates y refleciones en torno a la despenalización del aborto en Chile. Centro de Derechos Humanos, Universidad Diego Portales, Santiago, 2015. Págs. 209-227.

PISARELLO, Gerardo: Los derechos sociales y sus garantías. Trotta, Madrid, 2007. 
POWELL, Jefferson: "The Original Understanding of Original Intent". En: Harvard Law Review, Vol. 98, N 5, 1985.

SCHMITT, Carl: Teoría de la Constitución. Tecnos, Madrid, 2003.

SMITH, Peter: "How different are Originalism and Non-Originalism?". En: Hastings Law Review, Hastings College of the Law, University of California, Vol. 62, N 3, 2011. Págs. 707-736.

SOLUM, Lawrence: "What is originalism? The evolution of contemporary originalist theory”. En: Social Science Research Network, Georgetown University Law Center, 2011. Disponible en: http://dx.doi.org/10.2139/ ssrn.1825543 [Fecha última consulta: 6 de Diciembre de 2019].

THAYER, Willy: El fragmento repetido. Escritos en estado de excepción. Metales Pesados, Santiago, 2006.

VIVANCO, Ángela: "La objeción de conciencia como derecho constitucional. Una especial mención a la objeción de conciencia ante la despenalización de la interrupción voluntaria del embarazo en tres causales, propuesta en el caso chileno". En: Casas Becerra, Lidia y Lawson, Delfina (comps.): Debates y reflexiones en torno a la despenalización del aborto en Chile. Centro de Derechos Humanos, Universidad Diego Portales, Santiago, 2015. Págs. 180-208.

ZÚÑIGA URBINA, Francisco: "Reformas constitucionales para un Estado social y democrático de Derecho". En: Colección Ideas, Año 4, № 33, 2003. Pp. 27-28.

\section{Jurisprudencia del Tribunal Constitucional}

STC Rol N²250-2012, de 18 de junio de 2013.

STC Rol No 3016 (3026)-16, de 9 de mayo de 2016.

STC Rol N 3729-17, de 28 de agosto de 2017. 